\title{
Transition between ground state and metastable states in classical two-dimensional atoms
}

\author{
Minghui Kong, B. Partoens, and F. M. Peeters* \\ Departement Natuurkunde, Universiteit Antwerpen (UIA) Universiteitsplein 1, B-2610 Antwerpen, Belgium
}

(Received 14 June 2001; published 18 March 2002)

\begin{abstract}
Structural and static properties of a classical two-dimensional system consisting of a finite number of charged particles that are laterally confined by a parabolic potential are investigated by Monte Carlo simulations and the Newton optimization technique. This system is the classical analog of the well-known quantum dot problem. The energies and configurations of the ground and all metastable states are obtained. In order to investigate the barriers and the transitions between the ground and all metastable states we first locate the saddle points between them, then by walking downhill from the saddle point to the different minima, we find the path in configurational space from the ground state to the metastable states, from which the geometric properties of the energy landscape are obtained. The sensitivity of the ground-state configuration on the functional form of the interparticle interaction and on the confinement potential is also investigated.
\end{abstract}

DOI: 10.1103/PhysRevE.65.046602

PACS number(s): 45.05.+x, 61.46.+w, 73.22.-f

\section{INTRODUCTION}

Wigner suggested in 1934 that a liquid to solid phase transition should occur in a three-dimensional (3D) Fermi system at low densities [1]. The quest for the observation of such a Wigner crystal has been the object of very intense and continuous work. After the first discovery of Wigner crystallization of electrons on the surface of liquid helium [2], there has been considerable theoretical and experimental progress in the study of the mesoscopic system consisting of a finite number of charged particles, which are laterally confined by a parabolic potential and repel each other through a Coulomb potential. This system is the classical analog of the wellknown quantum dot problem. These quantum dots are atomlike structures that have interesting optical properties and may be of interest for single-electron devices. These systems and their configurations have been observed experimentally, and are important in solid-state physics, plasma physics as well as in atomic physics. The classical approach is valid for quantum dots in high magnetic fields where the kinetic energy of the electrons is quenched, or for other classical systems, such as laser cooled ions in a trap [3] that are realized by electric and magnetic fields, trapped ions cooled by laser techniques [4], ions in a radio-frequency (RF) trap (Paul trap) $[5,6]$ or a Penning trap [7-9] that can also serve as an illustration of 3D Coulomb clusters $[10,11]$. Very large Coulomb clusters have been created recently in strongly coupled RF dusty plasmas [12-14] that are like a two-dimensional (2D) layered system. Examples of 2D Coulomb clusters are electrons on the surface of liquid helium [15] and electrons in quantum dots [16]. The vortex clusters in an isotropic superfluid [17], vortices in superfluid $\mathrm{He}^{4}[18,19]$, vortices in a Bose-Einstein condensate stirred with a laser beam [20] and in superconducting grains [21] have many common features with those of 2D charged particles [22]. Colloidal particles dissolved in water [23,24] and placed between two glass plates are another example of an experimental system

\footnotetext{
*Email address: peeters@uia.ua.ac.be
}

where classical particles exhibit Wigner crystallization [25]. Very recently, macroscopic 2D Wigner islands, consisting of charged metallic balls above a plane conductor were studied and ground state, metastable states, and saddle point configurations were found experimentally [26].

In a finite system there is a competition between the bulk triangular lattice and the circular confinement potential that tries to force the particles into a ringlike configuration. Those configurations were systematically investigated in Ref. [27] and a Mendeleev-type of table for these classical atomlike structures was constructed. The spectral properties of the ground-state configurations were presented in Refs. [28,29] and generalized to screened Coulomb $[30,31]$ and logarithmic [30,32-34] interparticle interactions.

In the present paper we want to go one major step further and calculate not only all the different metastable states but also the saddle points between those local energy minima and the path followed by the particles to transit between those energy minima. The present work is motivated by recent experimental work [26] where it was found that: (i) some of the configurations did not agree with the previous theoretical published one, and (ii) they were able to observe some of the saddle points that are the key configurations for transition between different stable (ground or metastable) states. Therefore, we also investigated the stability of the ground-state configurations against the functional form of the confinement potential and the exact form of the interparticle interaction potential.

The present paper is organized as follows. In Sec. II, we describe the model system. In Sec. III, our numerical technique, used to obtain the ground and metastable states, is outlined. The technique we used to find the saddle point is similar to the Cerjan-Miller algorithm [35]. After the saddle points are found, we connect the saddle point to the global minimum or a local minimum by the "walking downhill" method. Section IV is devoted to the structural and static properties of the ground and metastable states for $N=1$ $\sim 40$. The configurations are analyzed and compared with available experimental data and the results of previous theoretical approaches. The dependence of the ground-state con- 
figuration [26] on the functional form of the confinement potential and the interparticle interaction is calculated for 9 and 16 particles. These dependences may be responsible for the discrepancies between some of the experimentally found configurations and the earlier theoretical results. The discussion on the saddle point is presented in Sec. V, and the connecting path from the ground state to the metastable states is found, and we investigate the completely geometric properties of the energy landscape. Our conclusions are presented in Sec. VI.

\section{MODEL SYSTEM}

The model system consists of identically charged particles interacting through a Coulomb repulsive interaction and moving in a $2 \mathrm{D}$ plane where they are confined by a parabolic potential

$$
H=\frac{q^{2}}{\varepsilon} \sum_{i>j} \frac{1}{\left|\vec{r}_{i}-\vec{r}_{j}\right|}+\sum_{i} V\left(\vec{r}_{i}\right) .
$$

The confinement potential $V(\vec{r})=\frac{1}{2} m^{*} \omega_{0}^{2} r^{2}$ is taken circular symmetric and parabolic, where $m^{*}$ is the effective mass of the particles, $q$ is the particle charge, $\omega_{0}$ is the radial confinement frequency, and $\varepsilon$ is the dielectric constant of the medium the particles are moving in. Note that for the quantum dot problem an additional term appears in Eq. (1), which is the kinetic energy of the particles, which is absent in our statical classical problem. Here the motion of the particles is restricted to the $(x, y)$ plane. To exhibit the scaling of the system, we introduce the characteristic scales in the problem: $r_{0}=\left(2 q^{2} / m \epsilon \omega_{0}^{2}\right)^{1 / 3}$ for the length and $E_{0}=\left(m \omega_{0}^{2} q^{4} / 2 \epsilon^{2}\right)^{1 / 3}$ for the energy. After the scaling transformations $(r$ $\left.\rightarrow r / r_{0}, E \rightarrow E / E_{0}\right)$, the Hamiltonian can be rewritten in a simple dimensionless form as

$$
H=\sum_{i>j} \frac{1}{\left|\vec{r}_{i}-\vec{r}_{j}\right|}+\sum_{i} V\left(\vec{r}_{i}\right)
$$

with $V(\vec{r})=x^{2}+y^{2}$ and which only depends on the number of particles $N$. The numerical values for the parameters $\omega_{0}, r_{0}, E_{0}$ for some typical experimental systems were given in Ref. [27].

\section{NUMERICAL APPROACH}

Due to the presence of the confinement energy and the electron-electron Coulombic interaction, a complete description of the cluster system is complicated and can't be obtained analytically. Therefore, we used the Monte Carlo simulation technique [36] that is relatively simple and rapidly convergent and provides a reliable estimation of the total energy of the system in cases when relatively small number of Metropolis steps is sufficient. However, the accuracy of this method in calculating the explicit states is poor in certain cases. It becomes more difficult for clusters with a large number of particles, which have significantly more meta- stable states. To circumvent this problem we employ the numerical technique of Newton optimization that was outlined and compared with the standard Monte Carlo technique in Ref. [28]. In this way, we are able to obtain not only the ground state but also metastable states. It also yields the eigenfrequencies and the eigenmodes of the ground-state configuration. Now only a small number of calculation steps is needed to obtain the same accuracy. Moreover, using the modified Newton approach, we can explore the stability of the system in its ground-state configuration through its spectrum.

By studying the characteristics of the energy landscape and the energy barrier between the different local minima, we are able to find the saddle point configurations that are very important and are the key configurations for transition between different stable states. The technique we used to find the saddle point is explained in more detail in Ref. [37], and is similar to the Cerjan-Miller algorithm [35]. After the saddle points are found, we connect the saddle point to the global minimum or a local minimum by the "walking downhill" method. In this algorithm the direction of the steepest gradient is followed to force the system to transit from the saddle point state to the local minimum state. Which minimum is finally reached depends on the initial step, therefore, we repeat this procedure several times to determine both minima that the saddle point state connects. Thus the connecting path followed by the particles to transit between those energy minima is found, from which the geometric properties of the energy landscape are obtained.

\section{GROUND STATE AND METASTABLE STATE}

In Table I, we list for $N=1,2, \ldots, 40$ the energy per particle $E / N$ in the ground state and in the metastable states, where we also list the energy difference with the ground state $\Delta E / N$. The configuration is indicated by the number of particles in the different rings, the position of the center of the ring and the radius of the different rings, the width of the ring that is defined as the difference of the maximum radius and minimum radius in the same ring, and the energy of the lowest three normal mode frequencies of the ground state are also given in Table I. This table is rather exhaustive and should be compared with a similar one published in Ref. [33] for a logarithmic interacting system.

For different values of $N$ there exist different possible values for $E / N$ that are nothing else than the metastable states. The difference in energy between the metastable and the ground state is given in the third column and the corresponding configuration in the fourth column. Note that with increasing $N$ the number of metastable configurations increases and in general (but not always) the widths of the rings for metastable configurations are larger and the central ring/particle is not exactly located in the center of the parabolic potential well. For sufficiently large $N$, the simple ring structure gradually disappears in the center and the triangular Wigner lattice appears. There is a competition between two types of ordering: ordering into a triangular-lattice structure (Wigner lattice) and ordering into a shell structure, which leads to clusters with interesting self-organized patterns that 
TABLE I. The ground state and the metastable states for $N=1, \ldots, 40$ Coulombic particles confined in a $2 \mathrm{D}$ parabolic well. We give the energies $(E / N), \Delta E / N$, the shell structure $\left(N_{1}, N_{2}, \ldots\right)$, the radius and width of the shell, and the lowest three normal mode frequencies of the ground-state configuration. The energy is in units of $E_{0}$, the coordinate is in units of $r_{0}$, and the frequency is in units of $\omega_{0} / \sqrt{2}$.

\begin{tabular}{|c|c|c|c|c|c|c|c|c|}
\hline \multirow[t]{2}{*}{$\mathbf{N}$} & \multirow[t]{2}{*}{$\mathrm{E} / \mathrm{N}$} & \multirow{2}{*}{$\begin{array}{c}\Delta \mathrm{E} / \mathrm{N} \\
\left(\mathrm{E}_{\text {metastable }}-\right. \\
\left.\mathrm{E}_{\text {groundstate }}\right) / \mathrm{N}\end{array}$} & \multirow[t]{2}{*}{ Configuration } & \multirow[t]{2}{*}{$\begin{array}{l}\text { Radius } \\
\text { of the ring }\end{array}$} & \multirow[t]{2}{*}{$\begin{array}{l}\text { Width of } \\
\text { ring }\end{array}$} & \multicolumn{3}{|c|}{ Lowest Eigenfrequency } \\
\hline & & & & & & 1 & 2 & 3 \\
\hline 1 & - & - & 1 & - & - & & & \\
\hline 2 & 0.75000 & - & 2 & 0.50000 & 0 & 1.41421 & 2.44949 & \\
\hline 3 & 1.31037 & - & 3 & 0.66090 & 0 & 1.41421 & 1.73205 & 2.44949 \\
\hline 4 & 1.83545 & - & 4 & 0.78219 & 0 & 1.25189 & 1.41421 & 1.86483 \\
\hline \multirow[t]{2}{*}{5} & 2.33845 & - & 5 & 0.88288 & 0 & \multirow[t]{2}{*}{1.02886} & \multirow[t]{2}{*}{1.41421} & \multirow[t]{2}{*}{1.94009} \\
\hline & 2.36556 & 0.02711 & 1,4 & $\begin{array}{c}0 \\
0.99280\end{array}$ & 0 & & & \\
\hline \multirow[t]{2}{*}{6} & 2.80456 & - & 1,5 & $\begin{array}{c}0 \\
1.05916\end{array}$ & 0 & \multirow[t]{2}{*}{0.91889} & \multirow[t]{2}{*}{1.41421} & \multirow[t]{2}{*}{1.72935} \\
\hline & 2.82476 & 0.02020 & 6 & 0.96968 & 0.07205 & & & \\
\hline 7 & 3.23897 & - & 1,6 & $\begin{array}{c}0 \\
1.12232\end{array}$ & 0 & 1.09890 & 1.41421 & 1.45239 \\
\hline 8 & 3.66890 & - & 1,7 & $\begin{array}{c}0 \\
1.18223\end{array}$ & 0 & 1.10688 & 1.22689 & 1.41421 \\
\hline \multirow[t]{2}{*}{9} & 4.08812 & - & 2,7 & $\begin{array}{l}0.43211 \\
1.30184\end{array}$ & $\begin{array}{l}0.02724 \\
0.16201\end{array}$ & \multirow[t]{2}{*}{0.12681} & \multirow[t]{2}{*}{0.77540} & \multirow[t]{2}{*}{0.91669} \\
\hline & 4.09426 & 0.00614 & 1,8 & $\begin{array}{c}0 \\
1.23909\end{array}$ & 0 & & & \\
\hline \multirow[t]{2}{*}{10} & 4.48494 & - & 2,8 & $\begin{array}{l}0.42649 \\
1.34879 \\
\end{array}$ & $\begin{array}{c}0 \\
0.17677\end{array}$ & \multirow[t]{2}{*}{0.08910} & \multirow[t]{2}{*}{0.97483} & \multirow[t]{2}{*}{0.98520} \\
\hline & 4.48816 & 0.00322 & 3,7 & $\begin{array}{l}0.56774 \\
1.41293\end{array}$ & $\begin{array}{l}0.05311 \\
0.14064\end{array}$ & & & \\
\hline 11 & 4.86467 & - & 3,8 & $\begin{array}{l}0.56042 \\
1.45220 \\
\end{array}$ & $\begin{array}{l}0.00270 \\
0.14305 \\
\end{array}$ & 0.02451 & 0.73727 & 0.83817 \\
\hline \multirow[t]{2}{*}{12} & 5.23894 & - & 3,9 & $\begin{array}{l}0.55937 \\
1.48975 \\
\end{array}$ & $\begin{array}{c}0 \\
0.14650 \\
\end{array}$ & \multirow[t]{2}{*}{0.53084} & \multirow[t]{2}{*}{0.89022} & \multirow[t]{2}{*}{1.15011} \\
\hline & 5.24204 & 0.00310 & 4,8 & $\begin{array}{l}0.66623 \\
1.54800\end{array}$ & $\begin{array}{c}0 \\
0.10544\end{array}$ & & & \\
\hline 13 & 5.60114 & - & 4,9 & $\begin{array}{l}0.66200 \\
1.58123\end{array}$ & $\begin{array}{l}0.00176 \\
0.11547\end{array}$ & $6.002 E-4$ & 0.75236 & 0.75546 \\
\hline \multirow[t]{2}{*}{14} & 5.95898 & - & 4,10 & $\begin{array}{l}0.65950 \\
1.61368\end{array}$ & $\begin{array}{l}0.01385 \\
0.13137\end{array}$ & \multirow[t]{2}{*}{0.04940} & \multirow[t]{2}{*}{0.79446} & 0.84578 \\
\hline & 5.96269 & 0.00371 & 5,9 & $\begin{array}{l}0.75410 \\
1.66586 \\
\end{array}$ & $\begin{array}{l}0.00947 \\
0.07368 \\
\end{array}$ & & & \\
\hline 15 & 6.30758 & - & 5,10 & $\begin{array}{l}0.75105 \\
1.69402 \\
\end{array}$ & $\begin{array}{c}0 \\
0.09015\end{array}$ & 0.45989 & 0.68255 & 0.75956 \\
\hline & 6.31554 & 0.00796 & $1,5,9$ & $\begin{array}{l}0.02923 \\
0.91617 \\
1.74361 \\
\end{array}$ & $\begin{array}{l}0.04167 \\
0.11835 \\
\end{array}$ & & & \\
\hline 16 & 6.64990 & - & $1,5,10$ & $\begin{array}{c}0 \\
0.91101 \\
1.76825\end{array}$ & $\begin{array}{c}0 \\
0.14050\end{array}$ & 0.49237 & 0.66241 & 0.92179 \\
\hline & 6.65235 & 0.00245 & 5,11 & $\begin{array}{l}0.74717 \\
1.72320 \\
\end{array}$ & $\begin{array}{l}0.00441 \\
0.12766\end{array}$ & & & \\
\hline & 6.65619 & 0.00629 & $1,6,9$ & $\begin{array}{c}0 \\
0.97881 \\
1.81945\end{array}$ & $\begin{array}{l}0.06197 \\
0.03724\end{array}$ & & & \\
\hline 17 & 6.98290 & - & $1,6,10$ & $\begin{array}{c}0 \\
0.96956 \\
1.84176\end{array}$ & $\begin{array}{l}0.00552 \\
0.07609\end{array}$ & 0.05416 & 0.54796 & 0.55927 \\
\hline & 6.98433 & 0.00143 & $1,5,11$ & $\begin{array}{l}0.00536 \\
0.90549 \\
1.79481 \\
\end{array}$ & $\begin{array}{l}0.00657 \\
0.16168 \\
\end{array}$ & & & \\
\hline 18 & 7.30814 & - & $1,6,11$ & $\begin{array}{l}0.00300 \\
0.96447 \\
1.86476 \\
\end{array}$ & $\begin{array}{l}0.00653 \\
0.10514 \\
\end{array}$ & 0.00614 & 0.65492 & 0.67820 \\
\hline
\end{tabular}


TABLE I. (Continued).

\begin{tabular}{|c|c|c|c|c|c|c|c|c|}
\hline & 7.31522 & 0.00708 & $1,7,10$ & $\begin{array}{c}0 \\
1.02998 \\
1.90946 \\
\end{array}$ & $\begin{array}{l}0.06694 \\
0.02564 \\
\end{array}$ & & & \\
\hline \multirow[t]{2}{*}{19} & 7.63193 & - & $1,6,12$ & $\begin{array}{c}0 \\
0.96261 \\
1.88679 \\
\end{array}$ & $\begin{array}{c}0 \\
0.13692 \\
\end{array}$ & \multirow[t]{2}{*}{0.66759} & \multirow[t]{2}{*}{0.70531} & \multirow[t]{2}{*}{1.09892} \\
\hline & 7.63280 & $8.7 \mathrm{E}-4$ & $1,7,11$ & $\begin{array}{c}1.12602 \mathrm{E}-4 \\
1.02314 \\
1.93083\end{array}$ & $\begin{array}{l}0.00329 \\
0.05476 \\
\end{array}$ & & & \\
\hline \multirow[t]{2}{*}{20} & 7.94961 & - & $1,7,12$ & $\begin{array}{c}0 \\
1.01819 \\
1.95219\end{array}$ & $\begin{array}{l}0.00619 \\
0.07245\end{array}$ & \multirow[t]{2}{*}{$1.031 E-4$} & \multirow[t]{2}{*}{0.62728} & \multirow[t]{2}{*}{0.69260} \\
\hline & 7.95623 & 0.00662 & $1,6,13$ & $\begin{array}{l}0.01041 \\
0.95822 \\
1.91011\end{array}$ & $\begin{array}{l}0.00777 \\
0.21495\end{array}$ & & & \\
\hline \multirow[t]{3}{*}{21} & 8.26588 & - & $1,7,13$ & $\begin{array}{l}0.00142 \\
1.01487 \\
1.97328\end{array}$ & $\begin{array}{l}0.01000 \\
0.13711\end{array}$ & \multirow[t]{3}{*}{0.00317} & \multirow[t]{3}{*}{0.63738} & \multirow[t]{3}{*}{0.71452} \\
\hline & 8.26645 & $5.7 \mathrm{E}-4$ & $2,7,12$ & $\begin{array}{l}0.39273 \\
1.12744 \\
2.01192 \\
\end{array}$ & $\begin{array}{l}0.03627 \\
0.19935 \\
0.15137 \\
\end{array}$ & & & \\
\hline & 8.26756 & 0.00168 & $1,8,12$ & $\begin{array}{c}0 \\
1.07321 \\
2.01156 \\
\end{array}$ & $\begin{array}{l}0.18661 \\
0.11052 \\
\end{array}$ & & & \\
\hline \multirow[t]{2}{*}{22} & 8.57418 & - & $2,8,12$ & $\begin{array}{l}0.39458 \\
1.17613 \\
2.06959\end{array}$ & $\begin{array}{c}0 \\
0.27077 \\
0.10297 \\
\end{array}$ & \multirow[t]{2}{*}{0.29341} & \multirow[t]{2}{*}{0.40180} & \multirow[t]{2}{*}{0.55690} \\
\hline & 8.57568 & 0.00150 & $2,7,13$ & $\begin{array}{l}0.38900 \\
1.12400 \\
2.03144\end{array}$ & $\begin{array}{c}0 \\
0.19724 \\
0.18137 \\
\end{array}$ & & & \\
\hline \multirow[t]{2}{*}{23} & 8.87758 & - & $2,8,13$ & $\begin{array}{l}0.38885 \\
1.16958 \\
2.08895 \\
\end{array}$ & $\begin{array}{l}0.00118 \\
0.24227 \\
0.14446 \\
\end{array}$ & \multirow[t]{2}{*}{0.12867} & \multirow[t]{2}{*}{0.40830} & \multirow[t]{2}{*}{0.58505} \\
\hline & 8.87859 & 0.00101 & $3,8,12$ & $\begin{array}{l}0.50794 \\
1.27214 \\
2.12689 \\
\end{array}$ & $\begin{array}{l}0.05120 \\
0.26208 \\
0.12204 \\
\end{array}$ & & & \\
\hline \multirow[t]{3}{*}{24} & 9.17590 & - & $3,8,13$ & $\begin{array}{l}0.50417 \\
1.26512 \\
2.14415\end{array}$ & $\begin{array}{l}0.00326 \\
0.19163 \\
0.14418\end{array}$ & \multirow[t]{3}{*}{0.02762} & \multirow[t]{3}{*}{0.40652} & \multirow[t]{3}{*}{0.55310} \\
\hline & 9.17756 & 0.00166 & $3,9,12$ & $\begin{array}{l}0.51335 \\
1.31367 \\
2.17908\end{array}$ & $\begin{array}{c}0 \\
0.22226 \\
0.09571\end{array}$ & & & \\
\hline & 9.17987 & 0.00397 & $2,8,14$ & $\begin{array}{l}0.38911 \\
1.16535 \\
2.10691 \\
\end{array}$ & $\begin{array}{c}0 \\
0.24188 \\
0.16950 \\
\end{array}$ & & & \\
\hline \multirow[t]{3}{*}{25} & 9.47079 & - & $3,9,13$ & $\begin{array}{l}0.50710 \\
1.30505 \\
2.19669\end{array}$ & $\begin{array}{l}0.01278 \\
0.19944 \\
0.11122\end{array}$ & \multirow[t]{3}{*}{0.11377} & \multirow[t]{3}{*}{0.50320} & \multirow[t]{3}{*}{0.52713} \\
\hline & 9.47292 & 0.00213 & $3,8,14$ & $\begin{array}{l}0.50283 \\
1.26038 \\
2.16111\end{array}$ & $\begin{array}{l}0.00983 \\
0.17317 \\
0.15226\end{array}$ & & & \\
\hline & 9.47485 & 0.00405 & $4,8,13$ & $\begin{array}{l}0.60037 \\
1.35438 \\
2.19750 \\
\end{array}$ & $\begin{array}{l}0.02163 \\
0.15541 \\
0.13994 \\
\end{array}$ & & & \\
\hline \multirow[t]{2}{*}{26} & 9.76273 & - & $3,9,14$ & $\begin{array}{l}0.50452 \\
1.29914 \\
2.21296\end{array}$ & $\begin{array}{l}0.00244 \\
0.18436 \\
0.12611\end{array}$ & \multirow[t]{2}{*}{0.10409} & \multirow[t]{2}{*}{0.56681} & \multirow[t]{2}{*}{0.61503} \\
\hline & 9.76383 & 0.00110 & $4,9,13$ & $\begin{array}{l}0.59791 \\
1.39030 \\
2.24911\end{array}$ & $\begin{array}{l}0.03559 \\
0.15296 \\
0.05624\end{array}$ & & & \\
\hline
\end{tabular}


TABLE I. (Continued).

\begin{tabular}{|c|c|c|c|c|c|c|c|c|}
\hline \multirow[t]{3}{*}{27} & 10.05086 & - & $4,9,14$ & $\begin{array}{l}0.59494 \\
1.38378 \\
2.26391\end{array}$ & $\begin{array}{l}0.01026 \\
0.13764 \\
0.12630\end{array}$ & \multirow[t]{3}{*}{0.01311} & \multirow[t]{3}{*}{0.37880} & \multirow[t]{3}{*}{0.56307} \\
\hline & 10.05273 & 0.00187 & $4,10,13$ & $\begin{array}{l}0.59876 \\
1.42670 \\
2.29743\end{array}$ & $\begin{array}{l}0.06133 \\
0.17691 \\
0.10036\end{array}$ & & & \\
\hline & 10.05382 & 0.00296 & $3,9,15$ & $\begin{array}{l}0.50456 \\
1.29489 \\
2.22843 \\
\end{array}$ & $\begin{array}{c}0 \\
0.19007 \\
0.14683\end{array}$ & & & \\
\hline \multirow[t]{2}{*}{28} & 10.33562 & - & $4,10,14$ & $\begin{array}{l}0.59556 \\
1.41936 \\
2.31219\end{array}$ & $\begin{array}{l}0.02917 \\
0.16578 \\
0.07189\end{array}$ & \multirow[t]{2}{*}{0.05682} & \multirow[t]{2}{*}{0.17410} & \multirow[t]{2}{*}{0.47678} \\
\hline & 10.33778 & 0.0022 & $4,9,15$ & $\begin{array}{l}0.59259 \\
1.37843 \\
2.27922 \\
\end{array}$ & $\begin{array}{l}0.01374 \\
0.12710 \\
0.12678 \\
\end{array}$ & & & \\
\hline \multirow[t]{3}{*}{29} & 10.61807 & - & $4,10,15$ & $\begin{array}{l}0.59296 \\
1.41346 \\
2.32654\end{array}$ & $\begin{array}{l}0.02873 \\
0.15640 \\
0.12364\end{array}$ & \multirow[t]{3}{*}{0.03911} & \multirow[t]{3}{*}{0.12706} & \multirow[t]{3}{*}{0.57988} \\
\hline & 10.61926 & 0.00119 & $5,10,14$ & $\begin{array}{l}0.67955 \\
1.49439 \\
2.35987\end{array}$ & $\begin{array}{l}0.05418 \\
0.14576 \\
0.08672\end{array}$ & & & \\
\hline & 10.6204 & 0.00236 & $4,11,14$ & $\begin{array}{l}0.60235 \\
1.45375 \\
2.35715 \\
\end{array}$ & $\begin{array}{l}0.01961 \\
0.34364 \\
0.20754 \\
\end{array}$ & & & \\
\hline \multirow[t]{3}{*}{30} & 10.89732 & - & $5,10,15$ & $\begin{array}{l}0.67715 \\
1.48825 \\
2.37299\end{array}$ & $\begin{array}{c}0 \\
0.11070 \\
0.10212\end{array}$ & \multirow[t]{3}{*}{0.29745} & \multirow[t]{3}{*}{0.48458} & \multirow[t]{3}{*}{0.56208} \\
\hline & 10.89852 & 0.00121 & $4,11,15$ & $\begin{array}{l}0.60536 \\
1.44557 \\
2.36996\end{array}$ & $\begin{array}{l}0.05952 \\
0.47214 \\
0.31619\end{array}$ & & & \\
\hline & 10.89999 & 0.00268 & $1,5,10,14$ & $\begin{array}{l}0.02842 \\
0.82995 \\
1.56500 \\
2.40474 \\
\end{array}$ & $\begin{array}{l}0.04494 \\
0.19679 \\
0.12020 \\
\end{array}$ & & & \\
\hline \multirow[t]{4}{*}{31} & 11.17388 & - & $5,11,15$ & $\begin{array}{l}0.67540 \\
1.52072 \\
2.41797\end{array}$ & $\begin{array}{l}0.03417 \\
0.13067 \\
0.09374\end{array}$ & \multirow[t]{4}{*}{0.02351} & \multirow[t]{4}{*}{0.11182} & \multirow[t]{4}{*}{0.27895} \\
\hline & 11.17433 & $4.52 E-04$ & $1,5,10,15$ & $\begin{array}{c}0 \\
0.82568 \\
1.55780 \\
2.41745 \\
\end{array}$ & $\begin{array}{c}0 \\
0.16498 \\
0.13735 \\
\end{array}$ & & & \\
\hline & 11.17541 & 0.00153 & $1,5,11,14$ & $\begin{array}{l}0.13069 \\
0.84077 \\
1.60637 \\
2.43703 \\
\end{array}$ & $\begin{array}{l}0.31263 \\
0.63425 \\
0.13594 \\
\end{array}$ & & & \\
\hline & 11.17559 & 0.00171 & $5,10,16$ & $\begin{array}{l}0.67428 \\
1.48265 \\
2.38703\end{array}$ & $\begin{array}{l}0.01149 \\
0.12077 \\
0.12035\end{array}$ & & & \\
\hline \multirow[t]{2}{*}{32} & 11.44658 & - & $1,5,11,15$ & $\begin{array}{l}0.01272 \\
0.82275 \\
1.58794 \\
2.46152 \\
\end{array}$ & $\begin{array}{l}0.00963 \\
0.18210 \\
0.13245 \\
\end{array}$ & \multirow[t]{2}{*}{0.02971} & \multirow[t]{2}{*}{0.18804} & \multirow[t]{2}{*}{0.45106} \\
\hline & 11.44793 & 0.00135 & $5,11,16$ & $\begin{array}{l}0.67326 \\
1.51515 \\
2.43064 \\
\end{array}$ & $\begin{array}{l}0.01889 \\
0.13987 \\
0.11569 \\
\end{array}$ & & & \\
\hline 33 & 11.71564 & - & $1,6,11,15$ & $\begin{array}{l}0.00316 \\
0.87730 \\
1.65369 \\
2.50507 \\
\end{array}$ & $\begin{array}{l}0.02335 \\
0.13683 \\
0.08796 \\
\end{array}$ & 0.06805 & 0.21724 & 0.41934 \\
\hline
\end{tabular}


TABLE I. (Continued).

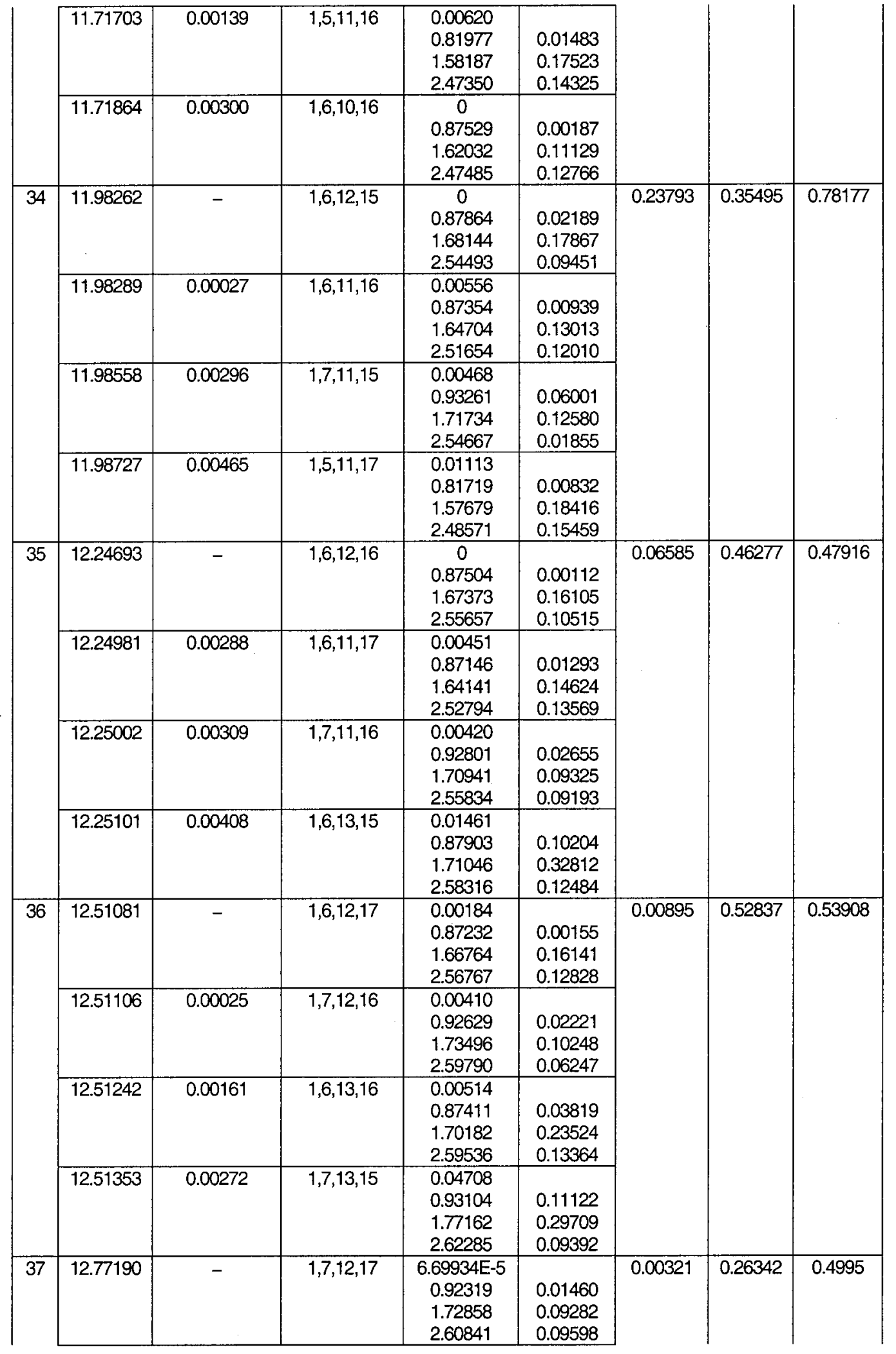


TABLE I. (Continued).

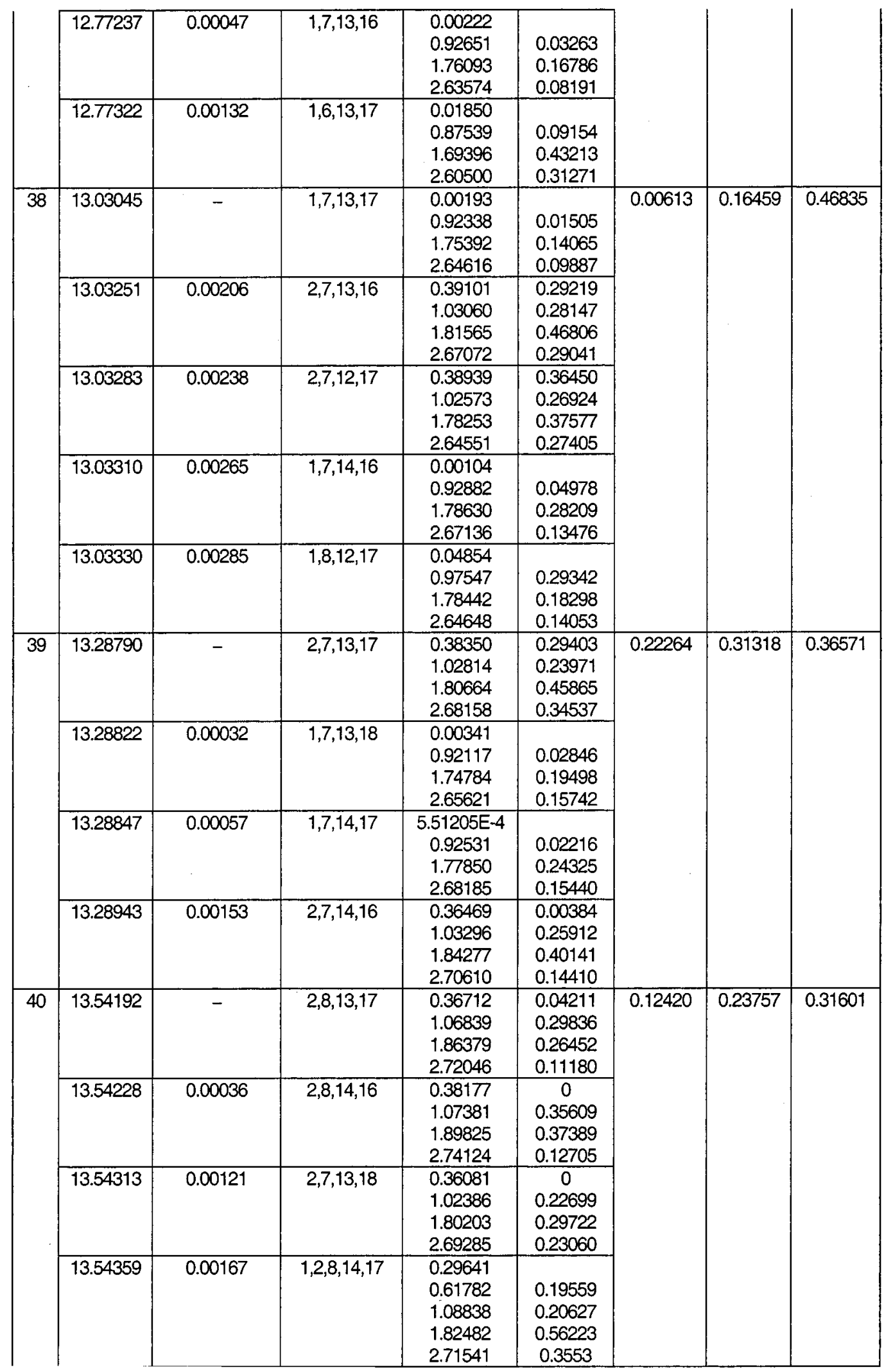




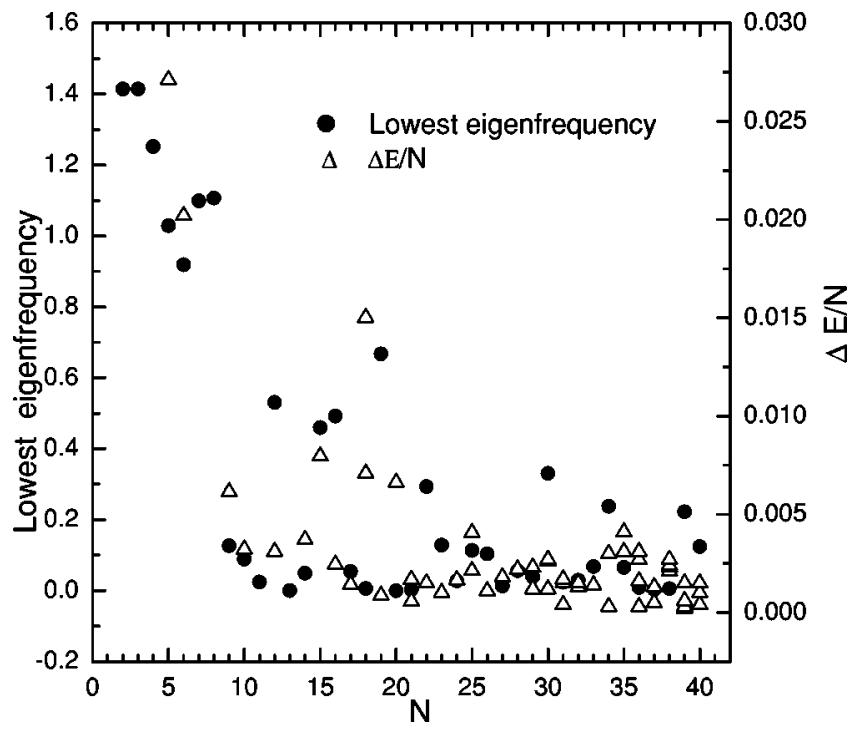

FIG. 1. The lowest eigenfrequency and $\Delta E / N$ as function of the number of particles.

show concentric shells at small $N$ and hexagonal cores surrounded by circular outer shells at large $N$.

The lowest nonzero normal mode frequency is a measure for the stability of the ground state, it tells us how easy or difficult it is to deform this state. Therefore, intuitively we would expect that the value of this frequency would be correlated to $\Delta E / N$, the energy difference between the first metastable and the ground state. Those values are plotted in Fig. 1 as function of $N$. Notice that there exist such a correlation in general, but that this is not true for all $N$ values, e.g., for $N=12,18,19,20,21,30$ there is no correlation.

The rings sometimes have a finite width that is shown in Fig. 2 as a function of $N$. Notice that the widths fall into

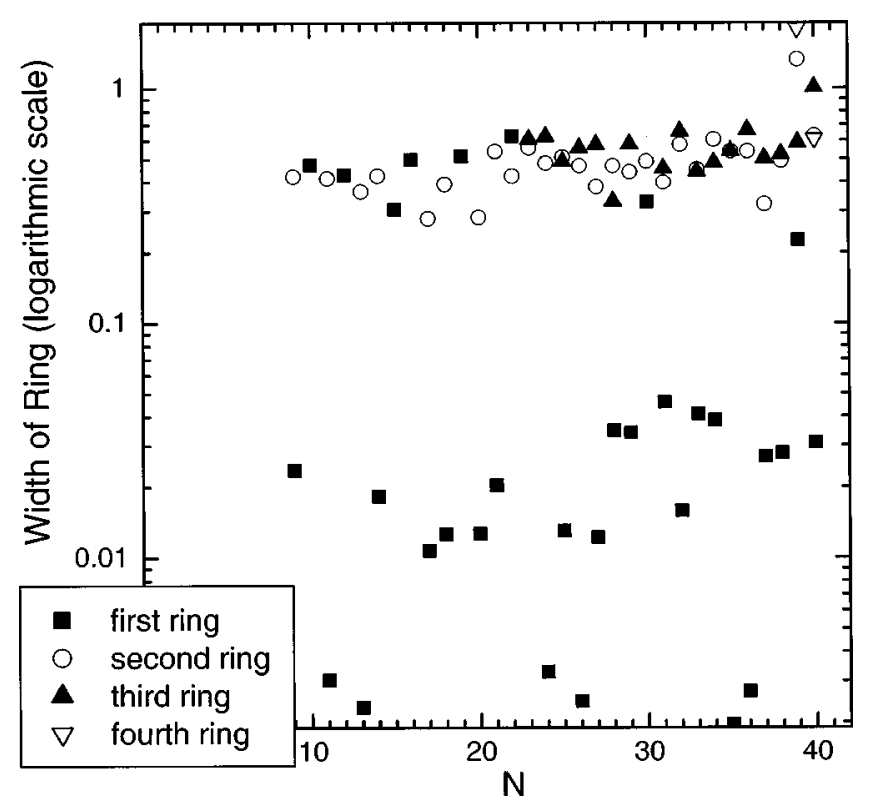

FIG. 2. The width of the different shells (logarithmic scale) as function of the number of particles.

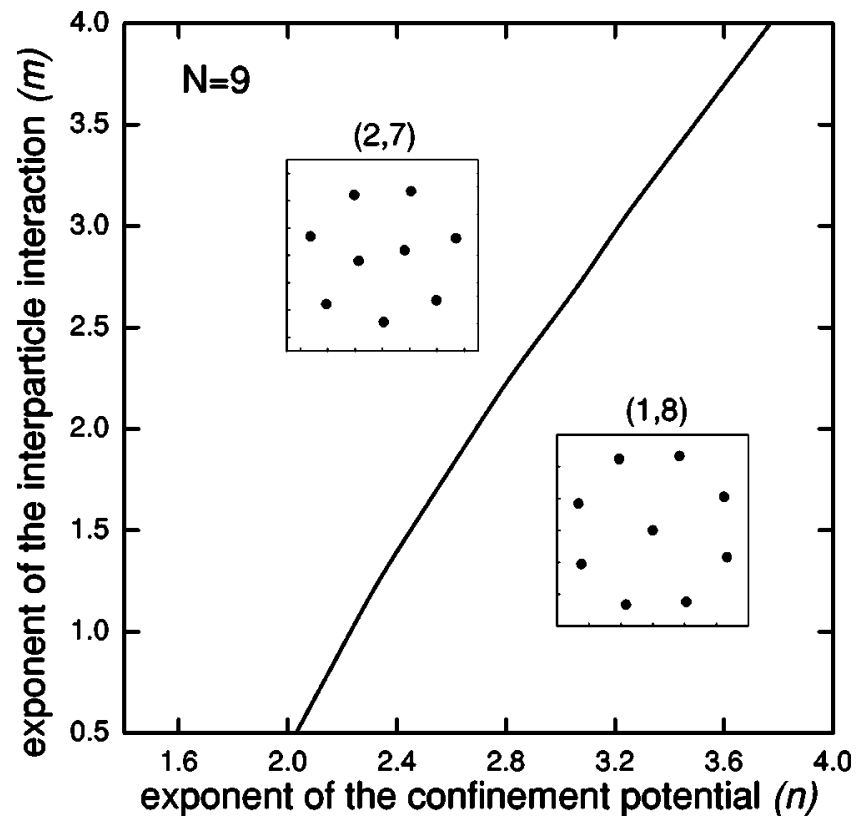

FIG. 3. The phase diagram for the ground state of nine particles. The dependence on the form of the confinement potential and the interparticle interaction is shown.

three bands; (i) width $\leqslant 0.003$, which is practically a perfect ring, (ii) width $\sim 0.02$, and (iii) width $\sim 0.5$. Usually, but not always, the outer ring has the largest width. The width of the rings increases with increasing $N$ and at the same time the widest ring becomes often the next to outer ring.

We compare our ground-state configuration with available experimental data [26] and the results of previous theoretical approaches $[27,30,32,33]$. For very small number of particles $(N<16)$, all theoretical and experimental results for the ground-state configurations are the same except for $N=9$ and 15 whatever kind of interparticle interaction. The experimental observation [26] for the ground state of nine particles is $(1,8)$ and for 15 particles it is $(4,11)$, which compares to our result $(2,7)$ and $(5,10)$, respectively. For $16<N<30$, the experimental result and all the calculated patterns present three shells. Our result differs from the experimental data of Ref. [26] for $N=16,17,20,22,24,25,27-30$. Because of the discrepancy between some of the experimental configurations and the "numerical exact" theoretical ground-state configurations it is possible that experimentally the interparticle interaction is not exactly a Coulombic potential and the confinement potential is not purely quadratic. Therefore, we investigated the effect of such deviations of these potentials on the ground-state configuration. As an example, we took $N=9$ and use confinement potentials $V \sim r^{n}$ and for the interparticle interaction $V \sim r^{-m}$. The resulting phase diagram is shown in Fig. 3. Notice that, depending on the values of $n$ and $m$, the system can be either in the $(1,8)$ or the $(2,7)$ configuration. For the harmonic confined Coulomb interacting system, i.e., $(n, m)=(2,1)$ the system is in the $(2,7)$ configuration but from the phase diagram it is clear that if we change the confinement potential slightly and make it more steep up to $n \geqslant 2.2$ the configuration $(1,8)$ becomes the 


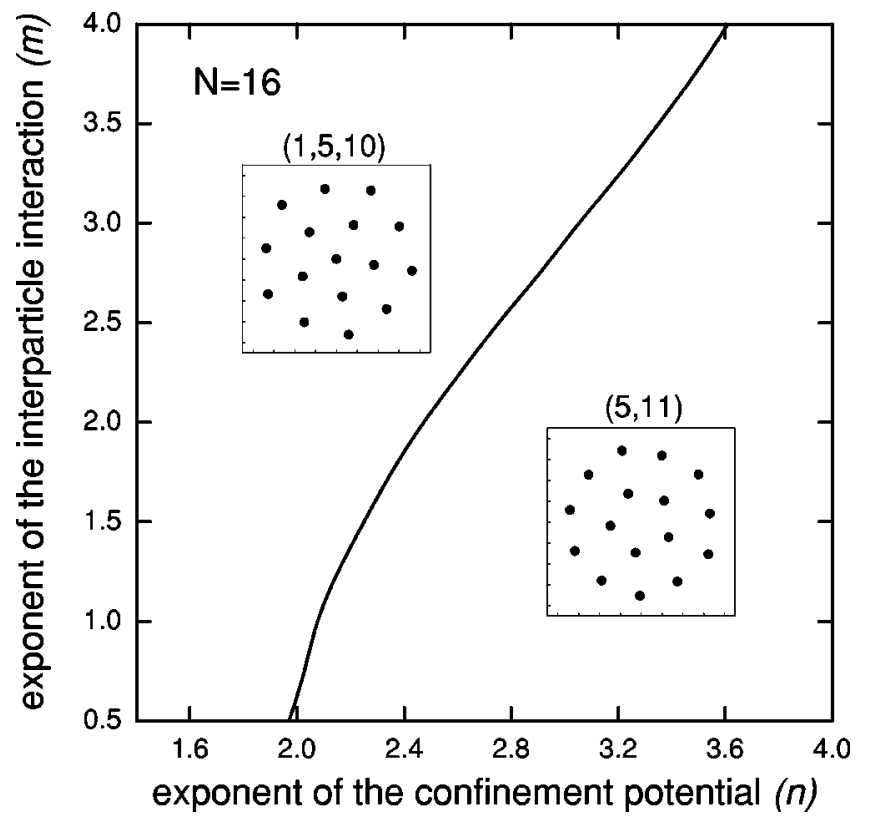

FIG. 4. The phase diagram for the ground state of 16 particles. The dependence on the form of the confinement potential and the interparticle interaction is shown.

ground state. The experimentally determined ground-state configuration for nine particles was $(1,8)[26]$.

There is also a difference with the experimental data and our results for $N=16$ particles. Therefore, we did the same investigation and present the phase diagram in Fig. 4. Notice that the harmonic confined Coulomb interacting system, i.e., $(n, m)=(2,1)$ is again close to the phase boundary between the configuration $(1,5,10)$ and $(5,11)$. This is probably the explanation why the experimental configuration [26] differs from our simulation results, since it is hard to guarantee that $(n, m)$ is exactly $(2,1)$ during the experiment.

Notice that for both $N=9$ and $N=16$ the metastable configuration has an energy very close to the one of the ground state, the difference is less than $0.2 \%$. These metastable configurations correspond indeed with the experimentally observed ones. Consequently, an alternative explanation for the difference with the experiment is that the experimental configuration got stuck in the metastable configuration.

\section{SADDLE POINTS}

Between metastable states and the ground state there are potential barriers. The system will prefer to transfer over the lowest potential barrier, which is the saddle point configuration between these energy minima, in order to transit from one stable configuration to the other. We plot in Fig. 5 the trajectories of the particles for the $N=5$ system making a transition from the ground state (5) to the metastable state $(1,4)$ and the saddle point connecting them. The trajectories of the particles can also be obtained by moving one of the particles to the center of the system.

For six particles, the ground state $(1,5)$ and the metastable state (6), corresponding to the hexagonal configuration, are obtained. Moreover, the unstable equilibria associated with

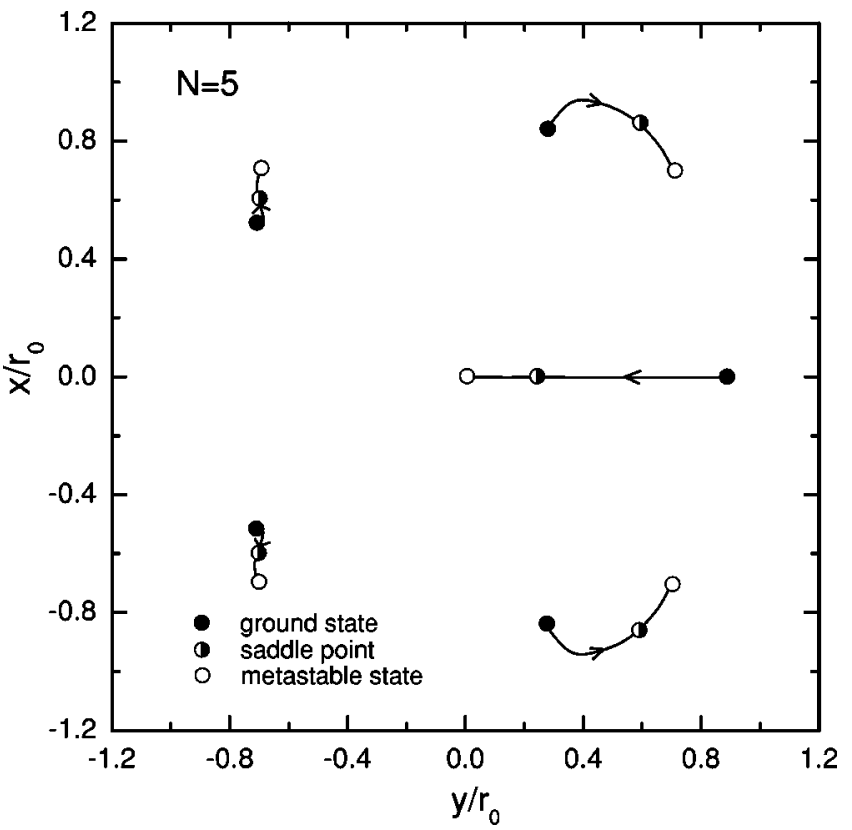

FIG. 5. The trajectories of the particles making a transition from the ground state to the metastable state and the saddle point connecting them for five particles.

saddle point configurations are also obtained, and the energy landscape is shown schematically in Fig. 6. Similar results for the $N=6$ energy landscape were found earlier [38]. There are two saddle points for this case, one of them is very close to the metastable state in both energy and configuration, and will therefore be hard to see experimentally [26]. In Fig. 6, the insets show the arrangement of the particles for the different states. Using the "walking downhill method," we found the central particle slowly moving to the periphery of the cluster. We would like to stress that the configuration with six particles on a perfect ring is a saddle point state in contrast to the claim made in Ref. [39]. This can be understood from the following simple model calculation: if three particles are placed on a circle with radius $A$, on the corners of an equilateral triangle, and the other three particles on another equilateral triangle's corners with radius $B$ rotated over $60^{\circ}$, the energy is

$$
E(c)=\frac{9}{2}\left(\frac{1+c^{2}}{36}\right)^{1 / 3}\left(\frac{1}{1+c}+\frac{1+c}{\sqrt{3} c}+\frac{2}{\sqrt{1-c+c^{2}}}\right)^{2 / 3},
$$

where $c=A / B$. This function is shown in Fig. 7. It is clear that the perfect circle configuration, i.e., $c=A / B=1$ is a saddle point, and that the minimum is obtained if three particles move a bit to the center, and the other three particles move away from the center (see the insets in Fig. 7). Both shown metastable states are connected by a rotation over $120^{\circ}$. The two minima in Fig. 7 correspond to the same configuration in which inner and outer ring are interchanged. Comparing our results with Fig. $2(N=6$ : ground state, 


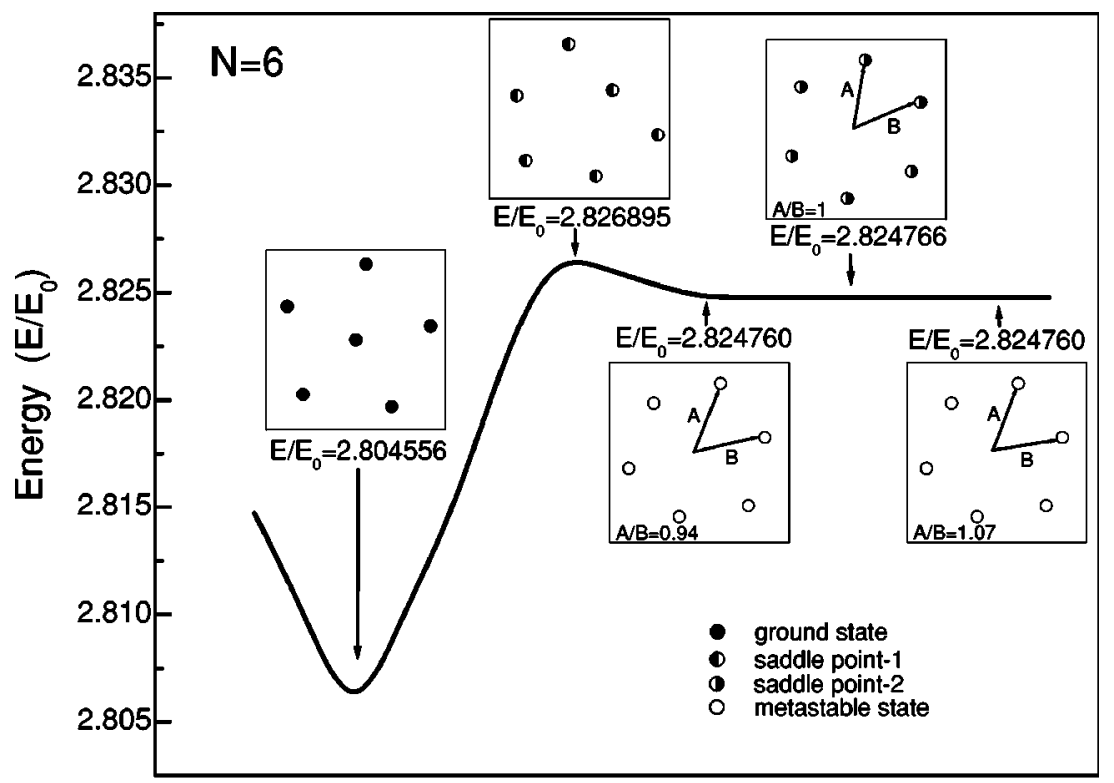

FIG. 6. The energy landscape and transition between the ground state to the metastable states for six particles.

\section{Path}

saddle point configuration, and the hexagonal metastable state) of Ref. [26], we see that the other saddle point is observed experimentally.

A list of the saddle point energies up to 20 particles is given in Table II. From this table, we notice that there is only one saddle point state for $N=3,4,5$ particles. But, on the other hand it is well-known that there are $(k-1)$ saddle points when there are $k$ minima. For $N=3$ and 4 one saddle point is found, although there is no metastable configuration. The reason is that the saddle point state connects two equilateral ground-state configurations that can be obtained from each other by a simple rotation. For the simple case of three particles, we show the energy surface and the corresponding configurations schematically in Fig. 8. Notice that there are always more saddle points than minima for $N>6$. With in- creasing the number of particles, more saddle point states are obtained and the energy landscape gets more complicated. For example, for nine particles, we obtain three saddle points and one metastable state. The results for the trajectories and energy landscape are shown in Fig. 9. Again, the groundstate configurations corresponding with the black and the white dot are connected by a simple rotation, i.e., a symmetry operation.

\section{CONCLUSION}

We presented the results of a numerical calculation of the configurations of the ground and all metastable states and their energies, for a system consisting of classical 2D charged particles that are confined in a parabolic confinement

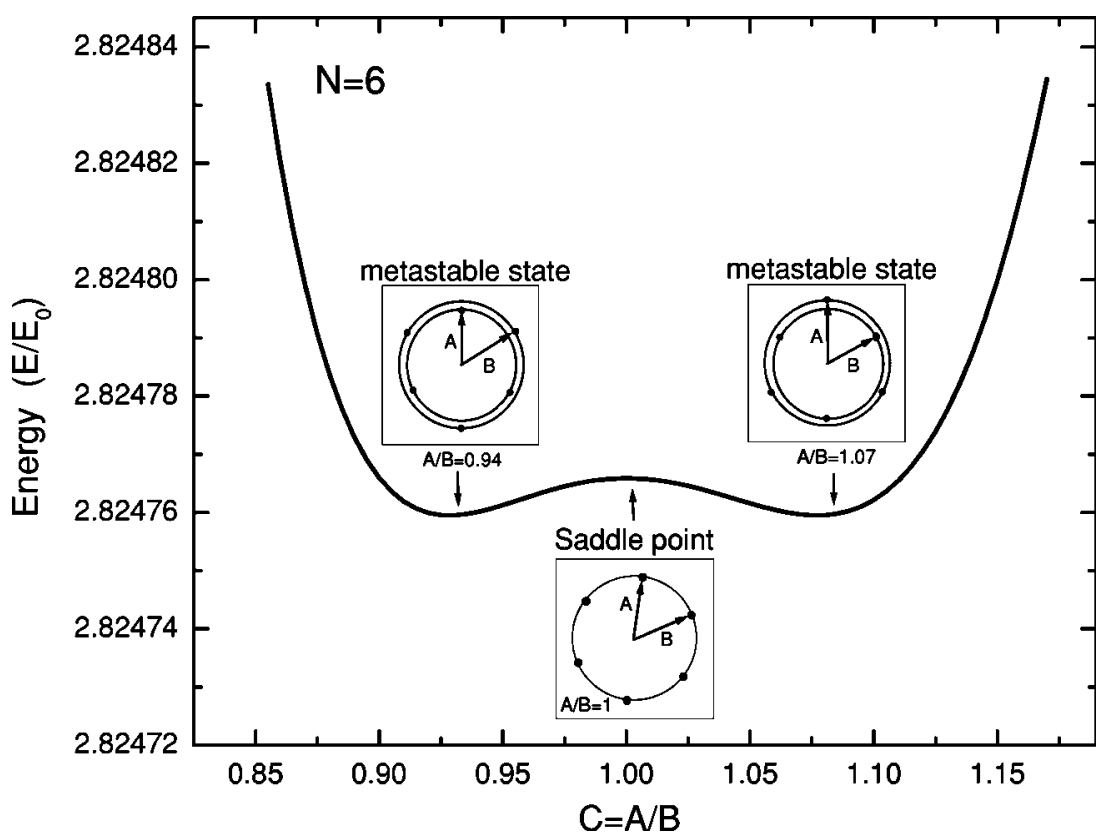

FIG. 7. Part of the energy landscape and corresponding configurations near the metastable state for six particles. 
TABLE II. The energies of the ground state, the metastable states, and the saddle point states for different number of particles $(N)$.

\begin{tabular}{|c|c|c|c|}
\hline $\begin{array}{l}\text { Number of Particles } \\
(\mathrm{N})\end{array}$ & $\begin{array}{c}\text { Energy of } \\
\text { Ground state }\end{array}$ & $\begin{array}{c}\text { Energy of } \\
\text { Metastable state }\end{array}$ & $\begin{array}{c}\text { Energy of } \\
\text { Saddle point }\end{array}$ \\
\hline 1 & - & $=$ & - \\
\hline 2 & 0.75000 & - & - \\
\hline 3 & 1.31037 & - & 1.46201 \\
\hline 4 & 1.83545 & - & 1.92064 \\
\hline 5 & 2.33845 & 2.36556 & 2.36829 \\
\hline 6 & 2.80456 & 2.82476 & $\begin{array}{l}2.82477 \\
2.82689\end{array}$ \\
\hline 7 & 3.23897 & $\cdot$ & $\begin{array}{l}3.27913 \\
3.28592\end{array}$ \\
\hline 8 & 3.66890 & - & $\begin{array}{l}3.68738 \\
3.68957\end{array}$ \\
\hline 9 & 4.08812 & 4.09426 & $\begin{array}{l}4.08813 \\
4.09530 \\
4.10628 \\
\end{array}$ \\
\hline 10 & 4.48494 & 4.48816 & $\begin{array}{l}4.48495 \\
4.48817 \\
4.48940\end{array}$ \\
\hline 11 & 4.86467 & $\cdot$ & $\begin{array}{l}4.87829 \\
4.87876 \\
4.88110\end{array}$ \\
\hline 12 & 5.23894 & 5.24204 & $\begin{array}{l}5.23955 \\
5.24209 \\
5.24368\end{array}$ \\
\hline 13 & 5.60114 & - & $\begin{array}{l}5.61202 \\
5.61529\end{array}$ \\
\hline 14 & 5.95898 & 5.96269 & $\begin{array}{l}5.96335 \\
5.97235\end{array}$ \\
\hline 15 & 6.30758 & 6.31554 & $\begin{array}{l}6.30832 \\
6.31534 \\
6.31577 \\
6.31617 \\
6.31689 \\
6.31702 \\
6.31769 \\
6.32205 \\
\end{array}$ \\
\hline 16 & 6.64990 & $\begin{array}{l}6.65235 \\
6.65619\end{array}$ & $\begin{array}{l}6.65117 \\
6.65490 \\
6.65547 \\
6.65620 \\
6.65648 \\
6.65706\end{array}$ \\
\hline 17 & 6.98290 & 6.98433 & $\begin{array}{l}6.98614 \\
6.98978 \\
6.98979 \\
6.99129 \\
6.99373 \\
6.99417 \\
6.99441\end{array}$ \\
\hline 18 & 7.30814 & 7.31522 & $\begin{array}{l}7.31522 \\
7.31535 \\
7.31700 \\
7.32046 \\
7.32095 \\
7.32154 \\
7.32390\end{array}$ \\
\hline 19 & 7.63193 & 7.63280 & $\begin{array}{l}7.63358 \\
7.63516 \\
7.64155 \\
7.64258 \\
7.64266 \\
7.64563 \\
\end{array}$ \\
\hline 20 & 7.94961 & 7.95623 & $\begin{array}{l}7.95637 \\
7.95638 \\
7.95639 \\
7.95640 \\
7.95641 \\
7.95654 \\
7.95693 \\
7.95695 \\
7.95709 \\
7.95725 \\
7.95739 \\
7.95817 \\
7.96316 \\
\end{array}$ \\
\hline
\end{tabular}




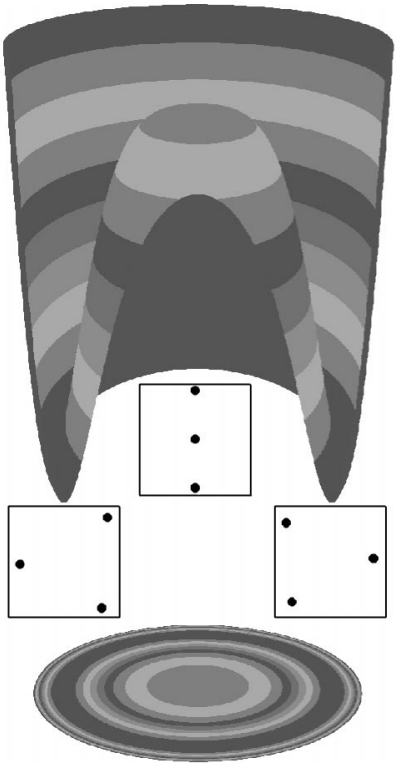

FIG. 8. Schematic view of the energy surface and projection of the energy and the corresponding configurations for three particles.

potential for $N=1, \ldots, 40$. These artificial atoms undergo configurational changes when the system transits from the ground state to the different metastable states, or between the different metastable states. Such transitions move through the lowest-energy barrier connecting those states, i.e., through a saddle point. The connecting path from the ground state to all metastable states is found and the geometric properties of the energy landscape were discussed.

Sensitivity of the configuration on the form of the confinement potential and the interparticle interaction is investigated and a phase diagram was obtained. This sensitivity on, e.g., the form of the confinement potential is probably the

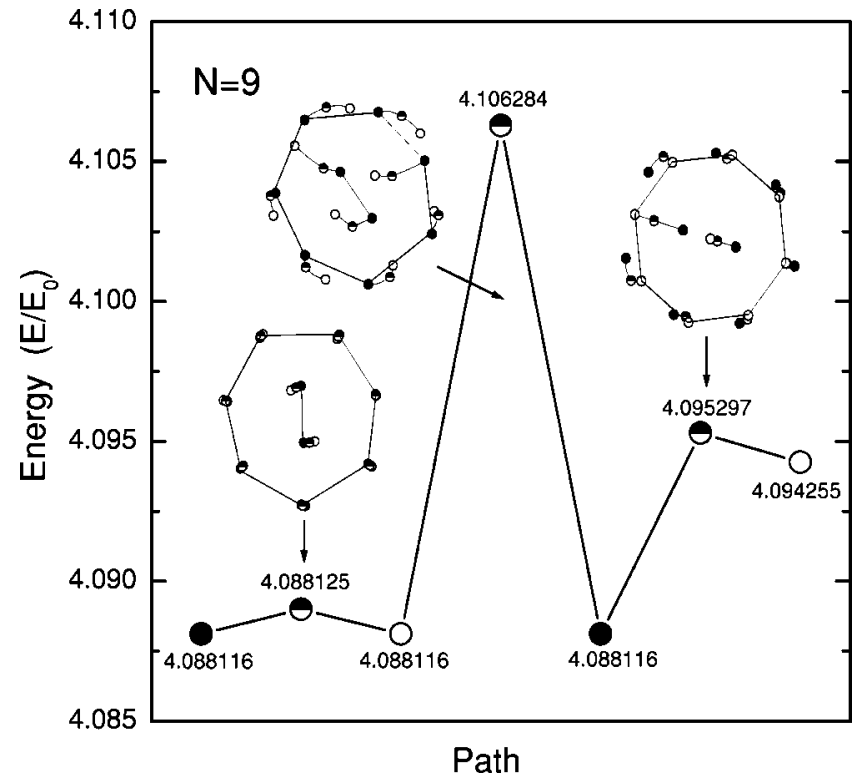

FIG. 9. The energy landscape and transition from ground state to metastable states for nine particles.

explanation why some of the recently found experimental configurations [26] differ from our simulation results.

\section{ACKNOWLEDGMENTS}

Stimulating discussions with Dr. J. Shi and M. Milošević are gratefully acknowledged. This work is supported by the Flemish Science Foundation (FWO-VI), the Belgian InterUniversity Attraction Poles (IUAP-VI), the "Onderzoeksraad van de Universiteit Antwerpen" (GOA), the EU Research Training Network on "Surface Electrons on Mesoscopic Structures," and INTAS.
[1] E. P. Wigner, Phys. Rev. 46, 1002 (1934).

[2] C. C. Grimes and G. Adams, Phys. Rev. Lett. 42, 795 (1979).

[3] D. J. Wineland and W. M. Itano, Phys. Today 40 (6), 34 (1987).

[4] S. L. Gilbert, J. J. Bollinger, and D. J. Wineland, Phys. Rev. Lett. 60, 2022 (1988).

[5] B. G. Levi, Phys. Today 41 (9), 17 (1988).

[6] F. Diedrich, E. Peik, J. M. Chen, W. Quint, and H. Walther, Phys. Rev. Lett. 59, 2931 (1987).

[7] A. Rahman and J. P. Schiffer, in Condensed Matter Theories, edited by P. Vashishta et al. (Plenum Press, New York, 1987), Vol. 2, p. 33.

[8] J. Beebe-Wang, N. Elander, and R. Schuch, Phys. Scr. 46, 506 (1992).

[9] D. H. E. Dubin and T. M. O’Neil, Phys. Rev. Lett. 60, 511 (1988).

[10] R. Rafac, J. P. Schiffer, J. S. Hangst, D. H. E. Dubin, and D. J. Wales, Proc. Natl. Acad. Sci. U.S.A. 88, 483 (1991).

[11] K. Tsuruta and S. Ichimaru, Phys. Rev. A 48, 1339 (1993).

[12] J. H. Chu and L. I, Phys. Rev. Lett. 72, 4009 (1994).

[13] H. Thomas, G. E. Morfill, V. Demmel, J. Goree, B. Feuer- bacher, and D. M. Möhlmann, Phys. Rev. Lett. 73, 652 (1994).

[14] W.-T. Juan, Z.-H. Huang, J.-W. Hsu, Y.-J. Lai, and L. I, Phys. Rev. E 58, 6947 (1998).

[15] P. Leiderer, W. Ebner, and V. B. Shikin, Surf. Sci. 113, 405 (1987).

[16] Nanostructure Physics and Fabrication, edited by M. A. Reed and W. P. Kirk (Academic Press, Boston, 1989).

[17] Y. Kondo, J. S. Korhonen, M. Krusius, V. V. Dmitriev, E. V. Thuneberg, and G. E. Volovik, Phys. Rev. Lett. 68, 3331 (1992).

[18] E. J. Yarmachuk and R. E. Packard, J. Low Temp. Phys. 46, 479 (1982).

[19] W. I. Galberson and K. W. Schwarz, Phys. Today 40 (2), 54 (1987).

[20] F. Chevy, K. W. Madison, and J. Dalibard, Phys. Rev. Lett. 85, 2223 (2000).

[21] D. Reefman and H. B. Brom, Physica C 183, 212 (1991).

[22] G. E. Volovik and U. Parts, Pis'ma Zh. Éksp. Teor. Fiz. 58, 826 (1993) [JETP Lett. 58, 774 (1993)].

[23] R. Bubeck, C. Bechinger, S. Neser, and P. Leiderer, Phys. Rev. Lett. 82, 3364 (1999). 
[24] I. V. Schweigert, V. A. Schweigert, and F. M. Peeters, Phys. Rev. Lett. 84, 4381 (2000).

[25] C. A. Murray and D. M. Winkle, Phys. Rev. Lett. 58, 1200 (1987).

[26] M. Saint Jean, C. Even, and C. Guthmann, Europhys. Lett. 55, 45 (2001).

[27] V. M. Bedanov and F. M. Peeters, Phys. Rev. B 49, 2667 (1994).

[28] V. A. Schweigert and F. M. Peeters, Phys. Rev. B 51, 7700 (1995).

[29] F. M. Peeters, V. A. Schweigert, and V. M. Bedanov, Physica B 212, 237 (1995).

[30] Y.-J. Lai and L. I, Phys. Rev. E 60, 4743 (1999).

[31] L. Cândido, J. P. Rino, N. Studart, and F. M. Peeters, J. Phys.: Condens. Matter 10, 11627 (1998).
[32] B. Partoens and F. M. Peeters, J. Phys.: Condens. Matter 9, 5383 (1997)

[33] L. J. Campbell and R. M. Ziff, Phys. Rev. B 20, 1886 (1979).

[34] P. Cheung, M. F. Choi, and P. M. Hui, Solid State Commun. 103, 357 (1997).

[35] C. J. Cerjan and W. H. Miller, J. Chem. Phys. 75, 2800 (1981).

[36] N. Metropolis, A. W. Rosenbluth, M. N. Rosenbluth, A. M. Teller, and E. Teller, J. Chem. Phys. 21, 1087 (1953).

[37] V. A. Schweigert and F. M. Peeters, Phys. Rev. Lett. 83, 2409 (1999).

[38] F. Bolton and U. Rössler, Superlattices Microstruct. 13, 139 (1993).

[39] G. Date, M. V. N. Murthy, and R. Vathsan, J. Phys.: Condens. Matter 10, 5875 (1998). 